\title{
Humanistic Values and Enlightenment Strategies of Global Society in the Potential of the Sustainable Development of Democracy
}

\section{Viktor Zinchenko}

Doctor of Sciences (Philosophical), Professor, Head of the Departament of Internationalization \& Principal Research Scientist of Higher Education of the Institute of Higher Education of the National Academy of

Pedagogical Sciences of Ukraine. Kyiv, Ukraine. zinchenko@kiev.com.ua

Abstract: In the article it is also analyzed the philosophical, educational, economic and political trends, perspectives and forms of further social sustainable development on the basis of creation of new forms of humanism.

In planning of the social changes the emphasis should be placed on the analysis of the humanistic values and on the analysis of new social institutions that will allow to understand the real mechanisms of the practical construction of a new global society. Institutional revolution should go far beyond the expectations of traditional social theory in depth and breadth. From the point of view of historical progress every new stage of human society evolution is quite different from the previous one that creates prerequisites for new material and spiritual integration of humanity.

We studied the specifics of post-industrial strategies of social development and transformation of social institutions, government management models in the context of globalization in today's industrialized systems. The article analyzes the dynamics and prospects of evolution of the self-organizing systems of society, governance, structure and functioning of the algorithm model of direct democracy and civilian government.

Keywords: global processes, deliberative democracy, social institutions, transitive development, postindustrial society, ideology, communication, critical theory of society, education, self-organization, transformation of the public sphere.

\section{INTRODUCTION}

Modern changes of the developed industrial society have led to the fact that a highly specialized analysis of the market mechanism can no longer provide a realistic idea of the structure of the social system: the state became an integral element of the functioning of the economy, and in a certain sense, the whole society is transformed into an economic apparatus, and vice versa, we observe a large-scale phenomenon of statepolitical interventionism in the economic system. Different elements of society are imbued with economic and political rationality. Instead of a monopolistic and oligopolistic market, the complicated structure of managed and interdependent processes came to replace the classical market economy.

In the transition to neo-capitalism («new industrial» or «post-industrial» society) the desire to stabilize the system reveals the insufficiency of just economic levers, there is a need for direct influence on the consciousness of the masses, in the creation of the general social market of spiritual production goods as an integrative, unifying social force. The scientific and technological convergention, the transformation of science into the direct production force, the revolution in the field of mass communication facilitates the implementation of this task. This has become a new historical step towards creating real prerequisites for both material and spiritual integration. 
Humanistic Values and Enlightenment Strategies of Global Society in the Potential of the Sustainable Development of Democracy

Modern neoindustrial society shows the ability to restrain social qualitative changes that would lead to the establishment of essentially different institutions, a new direction of production processes, new forms of human existence. This containment of social change is one of the notable achievements of a developed neo-industrial society. In the conditions of a developed industrial society, for the first time in the history of mankind science and technology provide the dominant social forces with such means of mass communication (and manipulation of the consciousness) of people that allow one-dimensional determination of the direction of their thoughts, especially socio-political beliefs, by modeling the types of behavior (first of all social), the needs with which the individual identifies himself and which in essence is a means of domination in the hands of the rulers.

\section{Materials AND Methods}

Today the question arose about the existence of man, culture, civilization. The consideration of the relationship between the global problems of humanity and the sensible means of their solution transforms into an allencompassing humanization problem of human and peace. Can the traditional understanding of progress with its emphasis on the continuous development of scientific and technical knowledge as domination over nature, the production of goods be regarded as the basis of democratic policy, if it in many areas becomes a barrier or even an obstacle to self-determining life in a solidarity society?

For the social theory the integration of developed societies in the modern «neo-capitalist» (or other terminology, «neo-industrialist») phase of their development is the subject of serious research that show how modern developed states can institutionalize and control social relations (in particular, in studies by J.Naisbitt, J.Habermas, R.Kurz, Th.Meyer, H.Marcuse, O.Lafontaine, A.Touraine and others).

This is primarily an analysis of global economic, political, ideological and social transformations, the functioning of ideology, management systems, education and upbringing, mass communication, methods of limiting social struggle within the formalized system, the development of institutions of society and market control.

A significant number of researchers of the «new industrial», «postindustrial», «informational» society (J.K.Galbraith, J.Naisbitt, J.Masuda, V.Ferkiss and others) of any rigid social, educational, political differentiations as the conditions for the emergence of a stable evolving civil society of a new type - polycentrary and synergistic. In this case, civil society is not just an association of free self-governing associations, but above all a society in which individual citizens are its main components, in which the ideas of equality in access to the basic values of the post-industrial society (information, science, education) reign, which can lead to the stabilization of civil society.

\section{RESULTS AND DiscusSiON}

As a result of the analysis of the contemporary world, socio-philosophical analysis, educational, economic and political researches and management practices discover some alien modes and forces in it, which not only failed to weaken, but moreover - modern human had fallen in such a tight dependence and danger that even the whole mankind threatens to turn itself into an object of unconstrained relations, but also jeopardizes the very foundations of human life on a global scale (Zinchenko 2015: 415-416).

Mankind was failed to avoid the threat of thermonuclear war; there were intensified difficulties in economic, cultural, spiritual, ethno-national development of countries of Asia, Africa, Latin America and Eastern Europe; the contradictory nature of the development of productive forces in industrialized countries has deepened, resulting in mass unemployment and a significant number of people living beyond the poverty line; fear and a sense of powerlessness of people grew in face of the technical and economic progress; actual environmental issues could lead to self-destruction of humanity. 
Humanistic Values and Enlightenment Strategies of Global Society in the Potential of the Sustainable Development of Democracy

The experience of the total integration of social groups based on "consensus agreement» (the term of Habermas) (Habermas 2002: 31) in non-capitalist societies makes the boundaries between social classes increasingly conditional. In an industrial society, industrial relations ultimately drop the burden of noneconomic forms, gaining relative independence from politics and, at the same time, such a way of regulation of the economic processes as an anonymous, price-regulated market. Economics and politics for the first time become autonomous spheres of social development, have the opportunity not to substitute one another, but only to limit one another (Habermas 1993: 14). Capitalism is already in the early stages of its development, creating a nationwide market for results of material production, unites, on the basis of this market, previously fragmented and distinctive civilian formations, subordinates them to a single central authority, introducing mandatory standards for the regulation of human life (mainly due to economic levers).

The conquest of economic, political and legal democracy led to the consolidation of civil-political liberties in the developed countries, the formal legal equality of all citizens, and a broad system of social protection. This condition is a convenient basis for the gradual formation of further, more effective social development. It is a question of changing the nature of society - complementing the existing social gains of an expanded system of self-government relations (in the social, industrial and political-state spheres), reducing the space of administration, mercenariness and exploitation. In the economic sphere of society it is necessary to take into account that one or another type of property as such does not contain public negation. The alienating, inhuman factor is ownership and exploitation regards to people and communities.

In the planning of the social future, the emphasis should be placed both on the analysis of values and on the analysis of social institutions, which will allow to understand the real mechanisms of practical construction of a new society. Social processes that sometimes appear to be surface phenomena actually characterize decisive tendencies that indicate not only other perspectives of change, but also a revolution that goes far beyond the expectations of traditional social theory in depth and breadth. From the point of view of historical progress, every new stage of human society evolution differs from the previous one that creates prerequisites for new material and mental integration of humanity.

The technical progress that has spread to the whole system of domination and coordination creates the forms of life and power that are suppressing forces, opposite to the system, and destroy or eliminate any protest in the name of the historical prospects of liberation from hard work and domination.In these conditions, manipulation of spiritual needs manifests itself only indirectly, as a derivative of economic and, in part, political manipulation.

New means of social integration, which open up a wider space for the exchange of activities and harmonious development of a person, dominant system put into service for their corporate interests. Subjected social mass to the ideological processing, it develops and implements standards of both material and spiritual life, forming $\mathrm{a}$ «mass culture» that suppresses the individual peculiarity of the mass consumer.

The purpose of this is the formation of a one-dimensional, uncritically thinking individual, alienated from the objective perception and even more - negative attitude to social reality. Not only the labor force, but all human values become a commodity, that is, human relations are objectified. This is also reflected in the language that becomes a mean of the expression and embodiment of the relation of domination and manipulation, to which the members of society are subordinated. One-dimensional thinking of a person considers the existing social reality as the best, as the embodiment of reason and as a capable to be always improved within its limits, within the framework of the fixed, protected by the ruling forces of the present. Critical thinking, in its analysis of reality, objectively discovers its potential, struggling to overcome this reality for the sake of exploiting and implementing more progressive possibilities for the realization of self-development of man and humanity on the way to further humanization. For one-dimensional thinking, a person is forced by the social need to identify 
Humanistic Values and Enlightenment Strategies of Global Society in the Potential of the Sustainable Development of Democracy

his personality, thinking, perception and surrounding things with their functions. Talking about anything, people «communicate with the language of their masters, philanthropists and authors of advertising texts. Therefore, they express not only themselves, their knowledge, feelings and intentions, but also something else. Describing «from their point of view», they describe what they are told to the media of mass communication - and this merges with what they really think, feel, see» (Marcuse, 1994: 207). In certain social situations, mass consciousness, recorded in the products of spiritual culture, primarily in the language, has a tendency to transform into an independent reality.

In wider spheres of social life, language directions are losing the form of an order, and through manipulation used by social technology, it is transformed so that subordinate persons themselves fulfill their duties consciously and freely. As a result, manipulation becomes a universal structure of spiritual repression, eliminating all forms of social criticism and effective opposition. «Forced control over the broad social spheres has organizational forms that promote the consolidation of a certain social situation, the smoothing of certain social problems, it brings about a long-standing institutionalized reform of some lifestyle, so that self-regulation of capitalism through «self-discipline» is possible» (Habermas 1971: 164) .

Under the conditions of «neo-capitalism», changes in the economy lead to the elimination of the impoverishment of hired workers, to the elimination of the former opposition between employees of physical and mental labor, and to a significant increase in the skills of the working class as a whole. In modern conditions, «the contradictions of globalism and imperialism» can not be summed up under the general formulas, such as «universal contradictions between labor and capital, and the more can not be solved by them» (Kurz 2001: 191). For modern society, there is a significant increase in the number of people who do not expect aid from politics to overcome fear and worries: not where economic power is often turned into a political one, nor where the free expression of opinions is debased - as in a capitalist state of «total prosperity» and in statebureaucratic «socialist» systems, creative activity of life is replaced by various forms of distraction from fruitful social activity. This ultimately leads to a massive escape from social structures, which, in turn, gives rise to new difficulties, dependencies, human passivity, devaluation of the individual as a responsible subject of social and historical creativity.

«Historically, we are again experiencing the period of Enlightenment that preceding the period of material change, that is, the period of education, which goes into practice» (Marcuse 1989: 83). It is the existence of operational relations that forms the ideological confidence in the necessary replacement of this type of society with others that are fundamentally different. This ideological confidence is periodically combined with the practical liberation movement and the activities of those social groups that have economic potential and organizational capabilities and have the ability to create a new society based on solidarity, cooperation, freedom, equality, and not on unlimited competition, the desire for personal self-affirmation in the struggle of all against all. The main opponent of these groups is currently considered bureaucracy, that is, those who exercise power over society on a monopoly basis, by avoiding effective control of the masses over it.

Critical social theory and models of deliberativeness, which, in particular, are developed within the conceptual directions of modern neomarxism and post-Marxism, are concentrated on the need for a thorough analysis of the phenomena of power and governance, of management models in the subsystems of society (economics, politics and the state). However, unlike other theoretical concepts, management practices and research programs, the purpose of the analysis of deliberative management is not exclusively to fix and give a description of the existing socio-state and economic and production data. On the contrary, a critical analysis of society involves the identification of existing antagonistic, alienating factors that disguide production and social communication. Critical social theory notes that at present in society (in all its spheres), in many aspects, there are false social needs that are imposed by certain social groups in order to discourage individual, group and creative freedom. 
Humanistic Values and Enlightenment Strategies of Global Society in the Potential of the Sustainable Development of Democracy

These needs establish a relationship of domination and subordination, producing exploitative labor, aggression, social conflicts, economic and social injustice. The stereotypes of the needs, behavior and social relations that promote the fixation of these relations are imposed. Marcuse calls it «repressive needs» (Marcuse 1993:15).

The functional manifestation of the domination situation in the field of management is an administrative model of management. The administrated public life and economic-industrial relations of this type are represented by the dominant structure as a standard of well-being and improvement. Neo-Marxism conceptually develops the theory of the need to change the exploitative and antagonistic relations between people in all spheres of social and individual life. The purpose of human development is the continuous historical progress to total freedom and the development of human emancipation. The relations of antagonism, built on the model of exploitation, primarily in the field of economics, lead to the emergence and preservation of the phenomenon of alienation, resist the human understanding and is the main catalyst for social conflicts.

The purpose of the analysis of deliberative philosophy, its critical theory of society and the model of management (including management of education) is to identify the key features and mechanisms of building a society in which there is no independent from the will of people social and industrial relations, that is, society, which abolished coercive relations and the dominance of some people over others. Control over production processes and social functioning should go to direct participants in social production (both in the field of material production and in the sphere of producing of ideas and management decisions).

Negative consequences of the repressive style of governance are clanhood and corporativeness, when the manager, the politician protects the interests of only his own group, representing them as allegedly common wealth. Delicate management in this regard points to the emergence in this case of one form of ideology namely, the ideological illusion of universality. As a result, there is the danger of the functioning of society in accordance with the rules and values of the ruling group (Gemeinschaft). Therefore, as noted by Harbermas, «social theory becomes a form of critique of ideology» (Habermas 1993: 20). Due to ideological manipulations, the relative independence of the individual (as in the economic activity in particular, so in the public sphere as a whole) comes to an end. He no longer has any free own thoughts: «The content of mass faith is a direct product of the bureaucracy that prevails in the economy and in the state and their supporters are secretly serving solely by their automated and therefore ineffective interests» (Horkheimer 1970: 52).

Ideology manifests itself as a «false consciousness» that is purposefully used by the dominant group for the spiritual subjugation of people, their subordination to the existing system. It also determines the formation of an individual «repressive thinking», which in its essence is uncritical in the perception of the already formed social activity. This is complemented by an organized system of manipulating mass consciousness with the assistance of mass media systems. Even standardized linguistic forms emerge as a tools of universal manipulation and whith purpose to establish a system of adaptation and subordination of people to the ruling group. Marcuse calls this situation repressive tolerance (conformity), as a result of which is formation an alienated consciousness (Marcuse 1989: 13).

This type of industrial society destroys interpersonal communication as its primary informal form, by means of bureaucratizing, isolating people, ignoring the world of human emotions. It is created a gap between technological and economic development of society, on the one hand, and its moral and ethical level, on the other. Negative consequence of this is the development of «social ignorance» of society, which suppresses the needs and aspirations of the individual. This leads to outbreaks of aggression and neuroticism. At the enterprise, it leads to social destruction (strikes, «runoff» frames, interclass collisions, industrial apathy etc.). In society it has a manifestations in revolution, riot, war, devaluation of socio-ethical values. It should be taken into account that «stocking» economic and social models do not allow to overcome the alienation between the participants in social and industrial relations. «Stocking» models involve the allocation of a participant in the relationship 
Humanistic Values and Enlightenment Strategies of Global Society in the Potential of the Sustainable Development of Democracy

with the possibility of obtaining a share of public or industrial profits. However, by providing the opportunity of ownership, they do not provide opportunities for participation in the management and control system. In this case, the employee at work or a citizen in a society at best becomes a «shareholder», which is a subject to the governing authority of the managers. Building a «society of consumption» and the establishment of formal legal equality does not help overcome alienation from the authorities and does not provide real chances for access to the management system. Irregular «participation» in the formation of decisions in the form of occasional participation in elections or the implementation of the adopted management decision-making, in the absence of management skills, leaves the person a passive participant in social and production processes, formed by a dominant ideology. The consequence of this development is a person's contemplative and performer position. The antagonistic-operational relations between people and above all in the field of direct communication are the main alienating factor, because in them a person does not appear as a unique person, but as a certain fetishized standard of prevailing economic and political ideology (Kockshott, Kotrell 2015: 111-112)

A person is able to control himself and act in solidarity with the pursuit of goals which achievement will contribute to the satisfaction of his individual interests.

The next step is a deliberative model of democracy and «communicative management». The goal of «deliberative communicative management» at the social, political and economic-production levels is to achieve a state of conciliation without conflict, based on concerted actions to satisfy common interests, participation of workers (production), and citizens (society) in the structures of governance. The purpose of the analysis of deliberative communication management is to identify the key features and mechanisms of building a society in which there are no public and industrial relations independent of the will of people, that is, in which abolished the coercion and domination of some people over others. Control over production processes and social functioning should go to people's direct participation in social production (both in the field of material production and in the field of producing ideas and management decisions). Previous objects of production and management (people) should become subjects of production, public organization and management with a view to realizing their own and collective, common needs and abilities. A system of joint incentives and mutual interest is created through joint participation in management, which ultimately acquires features of self-management. In this case, the rules and decisions can be legitimized on the basis of joint communication, which becomes the regulatory principle. The created structure should provide equal conditions for the equal choice of actions, excluding coercion and domination.

The goal is to achieve a democratic consensus in decision-making. At the level of society and enterprises, norms and decisions are formed as a result of compromise and contract (consensus) between all interested parties who have equal rights at equal access to management. At the same time, excessive pressure from one side is excluded, no privileged power-management position is granted to anyone. Consensus is achieved through the process of universal communicative decision making, which is based on the equal interests of everyone, are well-founded endorsement by all.

This model is called deliberative democracy (derived from the Latin term deliberatio - «discussion») Each individual in this model has the opportunity to participate in the elaboration of a strategy for the functioning of society, which leads to the consideration of the interests of individual individuals and social groups and helps to deepen their mutual understanding. Public cooperation is the result of mutual recognition, discussion and compromise, which means voluntary rejection of narrow personalistic, individualistic or group interests if they stand in the way of mutual consent, and this contributes to the expansion of openness in social, managerial and political communication.

Deliberative democracy of communicative management notes that one can not consider a truly legitimate decision based on a pre-made and approved formula of action and decisions (like, «I know what the people want» etc.). There is no single, pre-formed «will of the people». 
Humanistic Values and Enlightenment Strategies of Global Society in the Potential of the Sustainable Development of Democracy

The purpose of a deliberative model of management is the continuous reduction of mercenary-exploiting relations; expansion of the system of self-government (both at the public and at the enterprise level). In this case, the subject of social and labor relations is also the subject (and not the object) of the management, distribution and control system.

Destruction of the relations of domination reveals that a reasonable organization of society, which implies a critical theory, represents something more than a new form of management of the economy. «This affects more than the decisive factor, which makes society even more reasonable: the subordination of the economy to the needs of individuals» (Marcuse 1989: 105).

Society (and production) in the future should become self-governing. In place of the system of «human-thinghuman», the system of «human-human» must come, where relations will be directly social, reasonable. But such relations also require certain people - with conscienceness of adult person, able to navigate in all social relations. Self-management is carried out within the social systems through the inclusion of people in management and property, the expansion of rights and freedoms, the growth of social security, and the humanization of public life. A new society, thus, is a deliberately regulated and self-governing system.

Democracy in all forms of the public sphere is, above all, a communication that, in the process of broad discussion, rationally forms the will of its participants. That is, it is necessary to proceed not from predetermined views and decisions, but from the processes of their formation in the communicative discourse. The development of a new society should be carried out as a free matter of liberated individuals. For such a system, the principle of responsibility is the basic principle. To be able to take personal responsibility means submission to its requirements: being capable of being bound to be obliged. «Responsibility is an integral part of the freedom of the operating entity: I am responsible for my actions, regardless of whether there is an object of responsibility that - sooner or later - will bring me to it» (Dannemann 2005: 32). This stipulates the correspondence and dependence of the state of everyone for a similar state of another one. Equal to all, the level of freedom and justice is possible in the presence of solidarity: each member of the community must be responsible for his actions, engaging in similar responsibilities towards themselves from other members of community. There is a combination of self-responsibility and co-responsibility.

Along with the principle of responsibility, with such a system everyone also receives a particle of social or entrepreneurial income and management capabilities in proportion to the individual contribution to a joint case. It becomes an incentive and motivation for the creative, initiative self-development of each participant in social and production processes. This ensures the achievement of the goal of a democratic, deliberative community - the state of humanism, individual freedom and social solidarity instead of a state of conflict of socio-political and economic struggle, antagonistic irreconcilability and domination of exploitative relations. In the ideas of R.Kurz, H.Reichelt, J.Habermas, O.Lafontaine, M.Hammer, A.Negri, attention is drawn to the relationship between socio-collective actions, interpersonal interaction of creative people with the type of political ideology of society. An essential and substantiated claim seems to be that effective civic associations of any level and type are not based on decisions of the majority, and not even on the basis of consensus, but on the basis of the internal coherence of social orientations and values aspirations (Sintschenko 2017: 131).

Public reforms as an end in themselves are not capable to resolve the fundamental contradictions that break the world. There is also a need for radical revolutionary changes that can be achieved through massive actions and the development of self-organization and self-governance. Therefore, a deliberative economic and political concept retains in its arsenal the classical doctrine of a permanent social revolution (E.Mandel, A.Gorz, A.Badiou, M.Hardt), which implies the need for joint actions of society and humanity to solve the above-mentioned problems. The self-governing, deliberative society in the future may be (and should be) a global system, because at the level of an individual country only elements of a "civil self-governing (self-governing) society» are possible in one or another economic-political and social spheres. 
Humanistic Values and Enlightenment Strategies of Global Society in the Potential of the Sustainable Development of Democracy

The idea of a deliberative self-governing organization of society is the opposite to the command-administrative type of management, as well as to totally-deregulated systems. Democratic self-governming should be fairly flexible, that is, the masses should be able to freely choose from a variety of alternative projects, they must decide for themselves which part of the product should be distributed at a given level of society. The evolution of civil societal development, generated by social communicative-management models and humanistic ethical teachings, has led to a clear division of political and economic practices into the so-called «traditional liberal» and «subsidiary» currents in the modern period. Traditional democracy of the classical type in the economy and politics tends only to partial and insignificant corrections in the existing type of production, commodity relations and society, liberal in its essence, without changing its principles. This leads to economic-productional and social stagnation and the loss of political and ideological identity.

Subsidiary Deliberative Democracy (the term of the so-called «Subsidiary Social School», which covers social studies of such economists, sociologists, political scientists, lawyers as, in particular, R.Scholz and N.Trenkle, E.Lohoff, R.Kurtz and H.Reichelt, O.Laufontaine and T.Meyer etc.), considers the present state of society as temporary, transitional and staged, as requiring permanent integrated economic and political, socio-managerial and state-legal changes.

«Using any form of property to establish the relations of cooperation, solidarity - which combines both individual and public interests - on the contrary, contributes to the development of social and individual freedom on the basis of co-responsibility» (Kockshott, Kotrell 2015: 134).

In the social sphere, subsidiary deliberative democracy, based on its ideological principles, practical experience and the goal of total overcoming of the exploitation and alienation, can not afford to concentrate exclusively on purely share-based and parliamentary forms of economic and political activity. Because of the shareholderowner (economic sphere) and formally-parliamentary (political) activity are directed simultaneously:

1) on the formation of a group of capitalist owners, oriented for their purposes so-called «Ideal business purpose» - the desire to unlimited profit increase by any means (including anti-social ones);

2) by professional clan-type politicians who use the political control to lobby for their financial and industrial interests in the public activity. This may lead to the concentration of economic and political governance in the hands of certain closed-elite groups. It transforms management into a clan privilege. At the same time, it alienates from the administrative economic-political activity and management culture the broad segments of the population, whose activity in this case manifests itself episodically - during the receipt of dividends, elections, actions of civil disobedience, strikes or mass riots.

Deliberative democracy is in favor of involving the majority of the population in the day-to-day management economic and political activity of the population, covering whole sphere of economic and political enlightenment. The managerial economic and political activity of self-organization can occur in several forms.

The first form is the expansion of the so-called sphere «sociability» - the forms of activity of workers and citizens in the self-organization of self-government with their everyday, professional, creative life through the expansion of the sphere of free from the system of hierarchical power associations and associations in which people receive real control of their own destiny, taking into account the similar needs and rights of others. This leads to a combination of activities aimed at solving their own everyday household, professional and other narrow-group and class interests with the general public, which also stimulates the social and managerial activation of people. As a result, social, economic and political activity of all citizens is transformed from episodic to permanent, that is, that actively evolves.

The second form is the methods of social, economic-political pressure (actions of civil disobedience, strikes, revolutionary actions etc.) that make the essence of the sphere of governance and, in particular, the state and 
Humanistic Values and Enlightenment Strategies of Global Society in the Potential of the Sustainable Development of Democracy

its bodies protect from narrow-group needs for the function of the spokesperson and regulator of the collective and common interests. The managerial economic and political activity of self-organization does not allow conserving the social system and management methods, stimulates their evolution in the direction of constant democratization.

This leads to an increasimg dependence of managerial economics and politics on civil society, thanks to its continuous influence on the adoption of socially important decisions. Awareness of the possibility of its real influence on managerial processes, contributes to the formation of a «forward-looking reformational thinking» (Lafontaine 2008: 11) of representatives of social and managerial activities, which does not adapt to the existing economic and political reality, but, on the contrary, forms and directs its development. Since free, unrepentant thinking creates schemes and forms of future reform of society. It becomes a revolutionary factor, which determines the continuous humanization of society.

This will become possible when an absolutely dominant part of the social and production system will be directly covered by public control. It will mean a real victory of civil society in the basis of society, as diverse products of collective activity of associated members will cease to withstand each other. Only the objective development of production means, of production forces, of the market, management, only objectification of socialization of labor in various forms of its really necessary and beneficial cooperation can remove its social division. In the most rude forms this division alienates from human not only the results of labor, but also labor itself as his activity and as his self-development. In modern conditions of social technological and informative development, when different types of labor and its products do not oppose to each other irreconcilably as a generalization of interests of various social communities, and professional features through automation, informatization are unified, then the measure of the work itself gradually becomes its time which could be taken into account when it would be a distribution by labor.

In a number of neo-industrial countries, the system of self-governing civil society is gradually being implemented. This occurs where the cooperation of labor and distribution, socialization of property, production and political self-government become everyday practice, combined with the scientific and technological revolution, the globalization of the market, with the productive control of society over it, the integration of cultural and ethical values in universal human development. In its broadest sense, a civilized, deliberative society is the property of knowledge and of culture in general, that is, property of those living and working conditions that serve the development of not only natural or monetary wealth, but also the person himself as a fixed capital, including education, means of information and communication, various forms of intellectual and creative activity. This makes a person, above all, spiritually rich in the field of his individual self-development. Deliberative system is a socio-cultural factor, which includes the relation of human to means not only of material production, but also of self-production as a social, intelligent being. It seems to lead a human beyond the limits of direct material production, beyond his purely economic existence and the necessity to a wider social sphere of free and multilateral development.

In the idea of a deliberative society, the historical tendency of the transition to freedom from political and economic determinism is expressed, thus, a person becomes a co-owner of the general conditions of his personal development, regardless of the socioeconomic functions and roles that he performs. Reducing, thanks to science and technology, the necessary work, in a civil society environment, leads to an increase in the time for the complete development of the individual, which, in turn, himself, as the highest productive force, has a retroactive effect on the productive labor force.

Therefore, a deliberative society means not only the overcoming of subjugation, oppression and poverty, but a qualitatively new level of human freedom, freedom from purely economic necessity, dictated by the material needs. Public wealth is not just the property of everyone, but everyone, that is, such a common property, where 
Humanistic Values and Enlightenment Strategies of Global Society in the Potential of the Sustainable Development of Democracy

everyone is the owner of all social wealth in its full capacity (Kurz 2011: 43). As the freedom of everyone is a condition for the freedom of all, this wealth is first and foremost a science, a scientific knowledge that in reality can belong to everyone, without interfering with the possession of others by others. Scientific knowledge is essentially an all-inclusive production force, equally accessible to everyone.

There is a change in the system of views on scientific and technological progress as a cleverly controlled means to achieve the necessary material conditions for the implementation of moral-holistic marks. The progress of science and technology was understood as an improvement in the conditions of human life, and thus it was identified with social progress, the establishment of civil society. «Ultimately, people were supposed to understand that in the course of history, the plan of reason was not yet clear; on the contrary, the overwhelming prevalence of foolishness became increasingly apparent. In connection with the catastrophes of our time, the question was raised about the non-matching of scientific and technological progress with social» (Mark 2014: 107). It was allowed to identify the wisdom of human existence as a cultural-historical material-production rationality that does not go beyond utilitarianism and pragmatism. Without criticism of the instrumentalist mind it is impossible to analyze the interaction of technology and freedom.

As a separate entity, a person can be called moral only when he is capable of owning his aspiratons, but as a social entity, it is only then moralistic, when he economically and socially consciously keeps his needs under his control and conquers them for humane purposes. Peaple are themselves guilty of the creation of an inhuman type of «industrial society», which was the result of the non-humanistic orientation of their consciousness, and people as beings that are morally responsible for their own future they must solve these contradictions, which will reveal a path to their freedom. Only then the human will conquer the technical world and the threat that exists in it when he can confidently rise above this world, when he takes in his hands given to him material forces and will put it into service of the development of his freedom, when he can raise himself from the object to the subject of social forces, that is, when he, instead of the subject of manipulation, becomes a freelancer from the performer becomes a creator.

Radical self-government humanism is manifested in determining of the preconditions for the release of a person to true humanity. The humanistic orientation of man must be associated with the surrounding world, but to the extent that human does not renounce self-respect, with the world in which the economy, society and the state are humanized, «in which equality, freedom and brotherhood may not prevail as slogans, but as a living reality, and all this through support in the historical world of acting reality in terms of human dignity «(Meyer 2006: 109). But in turn this means practical relationships that can be brought to such a state in which the idea of a person comes to unity with the reality of its existence in a pluralistic industrial society. Modern economic, technological, political and social changes reflect the process of deep transformation of our world. The main question is not whether future changes will occur, but who will control this process.

«Since human is an open entity and various potential possibilities are laid down in him, everything depends on the conditions in which he exists. Thus, a new, more perfect system worthy of human is possible and at the same time necessary» (Schmidt 2008: 73). This objective opportunity and moral necessity are realized in the process of the common political and legal responsible activity of people in the formation of civil society. Stated in the relationship of interdependence, mutual benefit and mutual responsibility, driven not by fear and greediness, members of society gain their self-affirmation in the human dignity of socially identifiable personalities. «Citizens must understand the word «sociality» from the point of view of the dynamism of the consensus: social change itself is a value created by an agreement» (Ludtz 2013: 25).

The idea of freedom should become the benchmark for the liberation of human from natural and social burdens. Freedom implies not only the liberation from the humiliating dependencies of begging, oppression and fear, but at the same time it is also a requirement for everyone to develop his individual abilities, as well as to responsibly 
Humanistic Values and Enlightenment Strategies of Global Society in the Potential of the Sustainable Development of Democracy

individually participate as a socially mature person in shaping of value orientations, scientific and technical, cultural and spiritual knowledge, social progress. The civic system and the principles of democracy are aimed at such a society in which every person could freely develop his personality and participate responsibly in political, economic and cultural life.

Social activity, which is «based on the scale of equality, must be regarded as valuable, provided that it represents a process that rejects the perpetration of a personality and thus affirms justice, thereby making the verbally meaningful community a real one» (Habermas 1993: 30). Expressing respect for the equal dignity of the individuals, the responsible significance of justice in the first place comes from the effective concern of ensuring the ontological right to life in all its volume. «It requires equal freedom, equality before the law, equal opportunities in political and social life, as well as social protection and social equality» (Christoph 2009: 125).

«It is a new definition of a model of a social organization that would be compatible with the classical goals of civil society, legal policy, the gradual humanization and democratization of all social relations» (Meyer 2008: 55). Humanity came to the limit of irreversibility, to the other side of which is the possibility of inhumanity, nonfreedom and the overthrow of human dignity. The task is to realistically understand the specifics, the extent of human responsibility in these circumstances and realize it, because there was a qualitative increase in the value of existance, which determined the final relevance of our responsibility for it.

The formation of a humanistic future is possible not only on the basis of a clear idea of the global problems of the world, but also of such an understanding of progress that would be oriented towards the scale and criteria of true human values.

Finding harmony with society, nature and with people - this means overcoming alienation, dictating from the outside forces, oppression and the trade-industrial division of existence. This means replacing the state, the bureaucracy and the hierarchy with social and personal autonomy and self-government of individuals and their association, and replacing the competition and mutual struggle of the selfish people - with mutual solidarity, voluntary coordination of interests and needs.

Actualization of institutional social provision of the right at the level of justice is the willingness of each person to support each other, going beyond legal obligations. Thus, there is an emphasis on solidarity and co-responsibility as the basic values of civic will as the ascendant for free goal-setting. By giving the values of solidarity not only to the legal, anthropo-personal, but also to the political and cultural aspect, civilian democracy as a defining moment in approaching the value of human unity and fraternity points out that the weak one of any social group and planetary region should receive support for his right to life and worthy human existence. Without solidarity there can be no human society. «We can live free and equal in a humane society only if we are able to protect and support each other and will strive for freedom for everyone» (Fuchs 2013: 19). Only then will society and mankind begin to live better - more peaceful, more free, fairer and more solidary, only then will it survive. The human race will be able to save itself and the world around itself, only by establishing harmony between people and between human and nature, only by putting mutual aid and solidarity in place of competition and coercion, domination and suppression. But this is the equivalent of other, alternative to today's forms of people's relationships, and, therefore, a new society.

\section{CONCLUSIONS}

The interrelation of responsibility and progress is that the consciousness of mankind faced the need to develop a moral consciousness with inherent in it new approach to moral responsibility of a person who feels the negative effects of his activities and was on the brink of losing opportunities not only sustainable development, but also absolute degradation as a reasonable person: «Human domination has entered into a new dimentionality, becoming a total domination over its own family, when an individual became a hostage unlimited power of 
Humanistic Values and Enlightenment Strategies of Global Society in the Potential of the Sustainable Development of Democracy

someone else's forces and, in addition, faced with the need to live in a new way, which, taken together, means the highest degree of personal act of uniting responsibility» (Meyer 2008: 169). Responsibility for the present and future, the question of humanity progress is connected with the prospect of forming a existence worthy the person. Not every economic growth represents progress. It is necessary to consider the connection of economic growth on the basis of the scientific and technological revolution with the rethinking of responsibility for scientific and technological activities in terms of a specific danger to the human future. Transforming into global problems human activity, first of all in relation to nature, not only puts the world in front of the dilemma of progress or regress, but carries the ultimate foundations of existence or non-existence. Quantitative progress leads not only to the desired economic options, but in an evolutionary perspective, it can lead to the destruction of the whole human race.

Understanding a person as an unprogrammed, free, but at the same time in need of training throughout his life requires a rejection of the static understanding of freedom and progress. A person is free to act wisely, but he is also free to commit mistakes and freely correct them if they are corrected. Since uncertainty, imperfection, the ability to make mistakes and fall into the recurrence of inhumanity are purely human traits, then, according to the technique, the main driving force of social progress, must be designed in account of human errors. Hence, there is a moral need to check social and state processes, making changes in them and making them completely corrective. Existing social relations can be humanized because of cultural, legal and political progress that opens the way for social progress through reasonably oriented activities.

The humanitarian consequences of the use of social self-government is that, thanks to humanistic responsible thinking, it is possible to rationalize the formation of a civil system for the creation of social conditions for the free deployment of the individual.

\section{REFERENCES}

1. Маркузе,Г. Одномерный человек. Исследование идеологии Развитого Индустриального общестства. - K.-M.: REFL- book, 1994. - 368 c.

2. Christoph, K. (2009). Solidaritat. Baden-Baden: Nomos, 2009. - 223 s.

3. Dannemann, R. (2005). Das Prinzip Verdinglichung. Wiesbaden: Panorama, 2005. - 166 s.

4. Fuchs, A. (2013). Solidarität der Sozialpolitik. Bonn: Taschenbuch-Verlag, 2013.- 227 s.

5. Habermas, J. (2002). Legitimationsprobleme im Spatkapitalismus. Frankfurt am Main: Suhrkamp Verlag,2002. - $195 \mathrm{~s}$.

6. Habermas, J. (1971).Theorie und Praxis. Sozialphilosophische Studien. Berlin: Neuwied, 1971. - 303 s.

7. Habermas, J. (1993). Vergangenheit als Zukunft. Das alte Deutschland in neuen Europa. Zürich: Pendo Verlag, 1993 - $158 \mathrm{~s}$.

8. Horkheimer, M. (1970). Traditionelle und kritische Theorie. Fra.M.: Suhrkamp, 1970. - Fr. a.M., 1970. - 286 s.

9. Kockshott, P.W., Kotrell, A. (2015). Alternativen aus dem Rechner. Für sozialistische Planung und direkte Demokratie.-Köln:PapyRossa Verlag, 2015. - 267 s.

10. Kurz, R. (2011). Schwarzbuch Kapitalismus. Ein Abgesang auf die Marktwirtschaft. München: Ullstein, 2011. $-456 \mathrm{~s}$.

11. Lafontaine, O. (2008). Fortschritt und Solidarität. Bonn: Reinbek Verlag, 2008. - 228 s.

12. Ludtz, P. (2013). Die Ideologie des Sozialdemokratismus in der Sicht der Komunisten. - Hamburg: Das Vorwarts Buch, 2013. - 397 s. 
Humanistic Values and Enlightenment Strategies of Global Society in the Potential of the Sustainable Development of Democracy

13. Marcuse, H. (1993). Kritik der reinen Toleranz. Fr.a.M.:Suhrkamp Verlag, 1993. - 127 s.

14. Marcuse, H. (1989). Versuch über die Befreiung. - Fr.a.M.: Suhrkamp, 1989. - 133 s.

15. Mark, S. (2014). Dialektisches Denken in der Philosophie der Gegenwart. Die Ideen des Marxismus und die Reform der Demokratie. - Köln-Hannover: SPD-Verlag, 2014. - 224 s.

16. Meyer, Th. (2008). Grundwerte und Wissenschaft im demokratischen Sozialismus. Berlin/Bonn: J.H.W.Dietz Verlag, 2008. - $246 \mathrm{~s}$.

17. Meyer, Th. (2006). Grundwerte, Wissenschaft, konkrete Utopie. Hannover: Fackeltrager Vlg., 2006. - 287 s.

18. Schmidt, A. (2008). Beitrage zur marxistischen Erkenntnistheorie. Fr. a.M.: Suhrkamp, 2008. - 264 s.

19. Sintschenko, V.V. Globale Weltbild der Moderne auf dem Weg zu einem neuen Bewußtsein. Der homo oecologicus universalis («des globalen ökologischen Menschen») als gesellschaftlichen und wirtschaftsmodell//Creative Economics and Social Innovations. - № 1. - 7 (18). - 2017. - S.126-140.

20. Zinchenko, V. Institutional Aspects of Globalization and Regionalization in the Context of the Transformation of Society//Journal of Social Sciences and Humanities. - Vol. 1, No. 4, 2015. - P. 415-421.

Citation: Viktor Zinchenko. "Humanistic Values and Enlightenment Strategies of Global Society in the Potential of the Sustainable Development of Democracy". American Research Journal of Humanities and Social Sciences, vol 4, no. 1, 2018, pp. 1-13.

Copyright (C) 2018 Viktor Zinchenko. This is an open access article distributed under the Creative Commons Attribution License, which permits unrestricted use, distribution, and reproduction in any medium, provided the original work is properly cited. 